\title{
TOWARDS A BETTER KNOWLEDGE OF TRADITIONAL ENVIRONMENTAL DEVICES: COMPARISON BETWEEN TWO TRADITIONAL ALGERIAN HOUSES
}

\author{
A. Racha ${ }^{1, *}$, S. Kacher ${ }^{1}$ \\ ${ }^{1}$ Laboratoire Ville, Architecture et Patrimoine (LVAP), Ecole Polytechnique d'Architecture et d'Urbanisme (EPAU), Algiers, \\ Algeria - amraniracha@hotmail.fr, s_kacher@yahoo.fr
}

Commission II - WG II/8

KEY WORDS: Vernacular architecture, Traditional houses, Environmental devices, Comparative study

\begin{abstract}
:
It has been noticed that research is increasingly focused on exploring opportunities to use environmental devices of traditional origin to create more sustainable contemporary buildings. Unfortunately, this "neo-traditional trend" (Abdelsalam et al., 2013) is hindered by the performance of vernacular solutions, which are unable to meet the new needs of contemporary society. Advocates of this ideology believe that this situation is due to a lack of knowledge of these vernacular devices. From this point of view, this paper aims to establish a better knowledge of them for the purpose of improving their performance within contemporary buildings. Thus, it presents a comparison study between the traditional architecture represented by the Algiers Kasbah house and the M'zab valley house in Algeria. The choice of the case studies was made in light of the fact that notwithstanding the very opposite environmental contexts of each case study, they belong to the same typology of traditional houses called "house with wast ed dar". In fact, they share several similar environmental features such as the patio and the terrace. Even though initially there appear to be many similarities, some aspects of these devices vary from one environmental context to another. Therefore, this paper investigates the urban layout in which the houses are built as well as the principles of design and building materials in order to explore the impact of the physical and climatic conditions, referred to in this article as the "geo-climatic environment", on the environmental devices developed by each house. It compares the performance of these devices and how they respond to their geo-climatic environment in order to better understand their functioning mode which is the key of their successful adaptation to each environmental context and which could be the key to any future use of these vernacular devices in contemporary buildings.
\end{abstract}

\section{INTRODUCTION}

In this paper, the term environmental device refers to: any solution or good practice, relating to building design, materials and construction techniques, that is considered relevant to solving a given environmental constraint (Vida, 2011).

The main objectives of this paper are threefold. Foremost, to define the "physical factors" of the geoclimatic environment that are considered to have an impact on traditional architecture, both at the urban and architectural scales. Secondly, how can traditional architecture control these factors? Thirdly, what are the traditional environmental devices that can take advantage of these environmental factors, and where do the environmental devices developed by each case study coincide and differ?

\section{METHODOLOGICAL APPROACH}

Our approach consider that it is first necessary to define criteria of comparison which are in this case the physical factors of the geo-climatic environment and then move on to identify the passive environmental devices developed by each typology to respond to these factors. This approach relies foremost on literature review, mainly in which concern the description of study cases and the identification of the environmental devices. Also, it uses several other sources for collecting data about the geo-climatic environment of each site (Databases, Websites,...).

\section{GENERAL DESCRIPTION}

Algeria is a Mediterranean country and the largest country in Africa $\left(2,381,741 \mathrm{~km}^{2}\right)$. It comprises three main regions and climatic zones around its territory: the Mediterranean climate along the coast to the north, the semi-arid climate in the region of high plains and mountains in the middle, and the arid climate in the desert to the south. The first case study which is the "house of the Algiers kasbah" is located in the department of Algiers, capital of the country, in the northern part of Algeria in a coastal site with a Mediterranean climate, whereas the second one which is the "M'zab valley house" is located in the department of Ghardaia, about $600 \mathrm{~km}$ south of Algiers, in the septentrional part of the Algerian desert with an arid climate ${ }^{1}$.

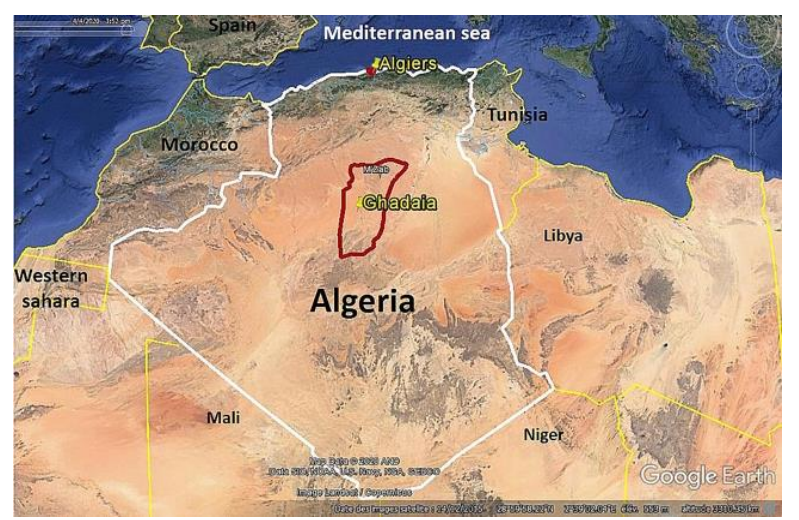

Figure 1. Location of case study sites on the map of Algeria (Google Earth, 2020 treated by the authors).

\footnotetext{
* Corresponding author

Algerian Archaeological Atlas.
} 


\subsection{The Kasbah of Algiers}

3.1.1 The site of the Kasbah of Algiers: This is the oldest site of the city of Algiers, inhabited since the 6th century BC by the Phoenicians ${ }^{2}$. It is located on a rocky hill overlooking the Mediterranean Sea on the western side of the Bay of Algiers (Corpus, Meda Programme, 2001).

The term Casbah, Kasbah or Kasaba refers to a "fortress" or "citadel". Originally, it refers to the highest point of the ArabMuslim medina, then the term was extended to designate the whole of the old city of El Djazair ${ }^{3}$ limited by the Ottoman ramparts built at the end of the 16th century ${ }^{4}$. The site was first declared a National Historic Site in November 1991, and then it was classified on the UNESCO list of World Heritage of Humanity in 1992. The zone classified covers an area of 54.7 ha and is located within the safeguarded sector erected subsequently, in 2005, in accordance with the Algerian law 98/04 (PPSMVSS Kasbah of Algiers, 2017).

The physical characteristics of the site influence its urban and architectural form as well as the microclimate within it. Thus, its topography requires an "east-south-east" orientation. Its abrupt physical limits prevent the city from expanding, leading to a horizontal and vertical densification of its urban structure (Ravéreau, 1989) resulting from the agglomeration of dense constructions, mainly Ottoman houses (Novelli, D'Ayala, 2012), which lean against each other creating terraces that slope towards the sea, following the slope of the land. The streets of the medina are narrow, generally in the form of stairs (Karabag, Fellahi, 2017), arranged in a hierarchical manner allowing a filtering of the passage from public to private space $^{5}$. They are sometimes equipped with a Sabbath, which is an overhang formed mainly by a K'bou ${ }^{6}$ or the imbrication of two $K^{\prime} b o u$ that cover the street with a floor or a vault.

3.1.2 The house of the Kasbah of Algiers: Three forms of traditional houses are distinguished in the medina of Algiers ${ }^{7}$ according to the form of their wast ed dar. The first form is the "House with patio" where wast ed dar, the patio, is an open-air courtyard surrounded by porticoes. The second form is the "House with chebak" or chebek, its wast ed dar is covered or semi-covered with a central opening in the roof equipped with a grid. Finally, the third form is Alwi or "Alaoui house", its wast ed dar corresponds to a space housing the drouj or the staircase and having a small central opening in the roof (Corpus, Meda Programme, 2001; Missoum, 2003). Apart from these differences, the three forms of houses share the fundamental characteristics (Figure 2).

First of all, the dwellings are two to three storeys high with a flat terrace $s t a h^{8}$. They take the form of an introverted dwelling with no windows overlooking the outside except for a few small openings. They are all accessible through a sqifa or a chicane which is an entrance space that constitute a transition between the public and the private space (Benchekroun et al., 2019).

https://whc.unesco.org/fr/list/565/

Ancient toponym of Berber origin of the city of Algiers (PPSMVSS Kasbah of Algiers, 2017).

https://whc.unesco.org/fr/list/565/

5 "Al tarik" is the main street of the city where production activities take place. "Al zenka" is a service alley with a few points of sale of basic necessities. "Al darb" or the dead end is a small alley serving the house.

6 Square space hollowed out of the back wall of a room, in front of its door opening onto the patio, and manifesting itself on the outside by an overhang (PPSMVSS Kasbah of Algiers, 2017).

7 There is also the house of the "Fahs" or the Algiers countryside; the houses of this group are not included in this paper in the light of the fact that they do not represent the way of life of the Algerian society
The rooms ${ }^{9}$ are long and narrow. They occupy the peripheral parts of the house and they are organized around an arched gallery called shin that surrounds the patio. Often, due to the slope of the terrain, the houses contain a basement that houses el $B i^{\prime} r$ or the well, el Jeb or the cistern and Bit al-Saboun or the laundry room. The orientation of the house depends on its position in the urban fabric, however, the main room of the house as well as el el Manzah ${ }^{10}$ always face the south-east to benefit from the sun (Belakehal et al., 2001; Missoum, 2003).

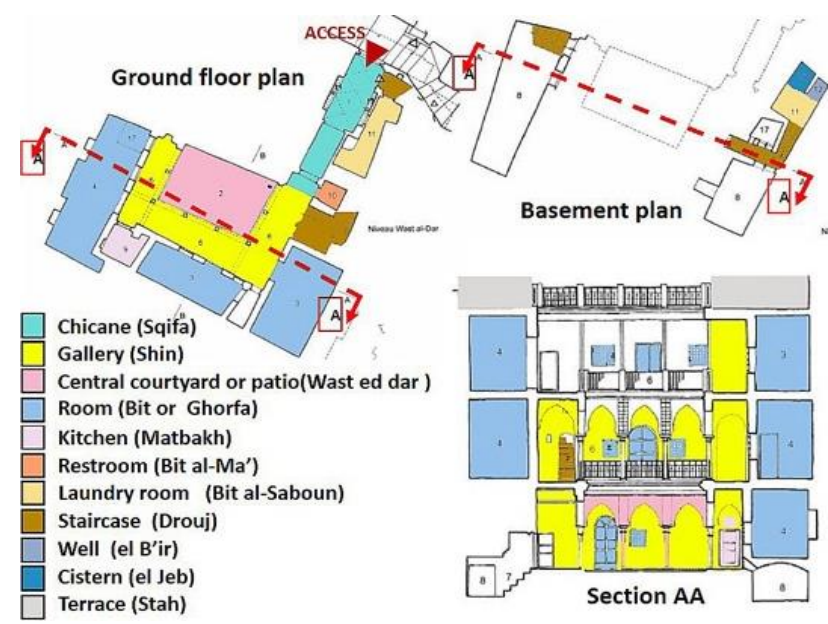

Figure 2. The architectural composition of a house with patio (Missoum, 2003; treated by the authors).

\subsection{The M'zab valley}

3.2.1 The M'zab Valley site: The M'zab Valley is a rocky limestone plateau crossed by the M'zab wadi. Its valley served as a refuge for the Ibadite Muslims who built, along the course of the M'zab wadi, five cities or "Ksour"11 between 1012 and 1350. The builders installed the cities on the rocky hills on either side of the wadi whereas assigning the soils bordering the wadi to the palm grove (Kitous et al., 2004; Chabi M., Dahli M., 2011a; Gouaich et al., 2018).

The Ksar, in the plural Ksour or K'sour, is a historical centre that characterizes the south of Morocco and Algeria. The term refers to a "fortified building" as well as the urban form of the southern city as opposed to the northern one: the medina (Nasri, 2007). The ksour of the M'zab Valley were declared World Heritage of Humanity in 1982. They cover a perimeter of $665.03 \mathrm{ha}^{12}$. In 2005 , the valley was erected as a safeguarded sector in accordance with the Algerian law $98 / 04^{13}$. The main characteristics of these Ksour are: the radio-concentric urban layout (like the Islamic medina), the dense and compact urban landscape as well as the narrow and winding streets covered and uncovered on successive sections (Kitous et al, 2004; Gouaich et al., 2018; Djebbar, 2018).

since they are reserved for the elite (Adli-Chebaiki, ChabbiChemrouk, 2015)

8 The houses are attached to each other and can communicate with each other via the stah (terraces) facing the sea (Benchekroun et al., 2019).

9 The rooms are called ghorfa when they are on the ground floor and bit when they are upstairs (PPSMVSS Kasbah of Algiers, 2017).

10 A room that occupies the western part of the terrace, used for domestic activities during the winter season (Belakehal et al., 2001)

11 The ksours are classified chronologically as follows : El-Atteuf (Tajnint), Bounoura (At Bounour), Ghardaïa (Taghardaï), Béniisguen (At Izjène), Mélika (At M'Lichet).

12 https://whc.unesco.org/fr/list/188/

13 Montada, Guide of historical sites and monuments of the M'zab valley 
3.2.2 The house of the M'zab Valley: In the garden cities of the M'zab Valley there are two forms of houses. The first form is integrated into the urban fabric of the ksour of the M'zab pentapolis. The second form is a summer house built in the palm grove of each ksar (Corpus, Meda Programme, 2001). Apart from the massive aspect of the house of the palm grove and the integration of palm trees within it, both forms retain the fundamental characteristics shown in (Figure 3).

The house of the M'zab valley is an introverted dwelling with the exception of a few slits overlooking the outside (Ravéreau, 2003). It is built on two or three levels with a flat terrace (Adad, Mazouz, 2013). The main characteristic of the Mozabite house is the fact that it contains two wast ed dar. The first one is called in Berber Amesentidar and it occupies the daia or the ground floor. The second one is called Tigharghart ${ }^{14}$, it is located on the upper floor or Emess Enej. In the daia we find, first of all, the chicane, called Taskift, which leads to the Amesentidar. This latter is a central courtyard covered over its largest area and that has a small opening with chebek or grid in the center of its roof allowing air and light to enter the house (Bousquet, 2002). It is also a point of convergence and distribution of other spaces such as the loom space, the kitchen, the restroom, called Ajmir, and the Tizefri ${ }^{15}$.

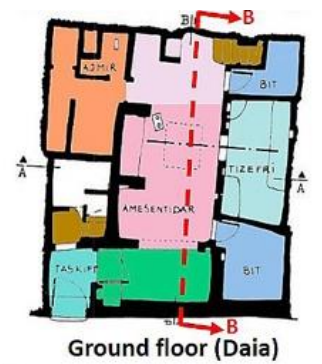

Chicane (Taskift)

Gallery (Ikomar)

Wast ed dar ( Am

Room (Tazkaa)

Kitchen

Restroom (Ajmir)

Staircase (Drouj)

Terrace (Stah)

El Ali

Figure 3. The architectural composition of a M'zab house (Bousquet, 2002; treated by the authors).

The Emess Enej, on the other hand, contains almost the same spaces as the daia with the exception of the Tigharghart which is a patio entirely open to the sky and surrounded by the Ikomar. This latter is a south-facing arched gallery used for sleeping and drying clothes. It houses the second kitchen as well as another Ajmir and gives access to the rooms, called Tazkaa. Often, these houses contain a space called $E l a l i^{16}$. It refers to a richly decorated male reception area with a few openings to the outside. It is accessible by a staircase isolated from the rest of the house (Corpus, Meda Programme, 2001; Belakehal et al., 2001; Bousquet, 2002; Bellal, Tacherifte 2003).

14 Berber word meaning "Upper centre" (Bellal, Tacherifte, 2003)

15 A room opening onto the patio, facing south-east, usually reserved for women guests (Belakehal et al., 2001; Adad, Mazouz, 2013).

16 If this space is on the ground floor, it is called "Houdjrat" (Bellal, Tacherifte, 2003)

17 United Nations Food and Agricultural Organization (Rodriguez, 2013)

18 A climatic Database to be used in combination with the CROPWAT computer program and allows the calculation of the water needs of harvest for a number of climate stations worldwide (Rodriguez, 2013)

19 A tool to help decision-making, developed by the Land and Water Development Division of FAO (Rodriguez, 2013)

\section{THE RESPONSE OF TRADITIONAL ARCHITECTURE TO THE PHYSICAL FACTORS OF THE GEO-CLIMATIC ENVIRONMENT}

This section is divided into two parts, the first attempts to define the physical factors of the geo-climatic environment and the relevant traditional response to these factors. The second part addresses the identification of the environmental devices developed by each case study. This part is carried out in two stages. First, we will present, in a general way, the good practices undertaken in response to the environmental constraints at the urban scale. Then, at the architectural scale we will try to present the environmental devices corresponding to each physical factor and define where they coincide and differ. The geoclimatic data, collected mainly from FAO's ${ }^{17}$ Climwat $^{18}$ database and Cropwat ${ }^{19}$ software, Geoconfluences ${ }^{20}$, Climate-data.org ${ }^{21}$, are presented in (Table 1).

\subsection{Definition of the physical factors:}

According to (Viaro, Ziegler, 1983), traditional architecture is subject to a set of factors arising from social life and productive activities as well as the geo-climatic environment which includes climate, site and building materials. On the basis of literature review, we have defined five climatic factors as well as the geographical variables that influence them, both of which are considered to have an impact on traditional architecture, at the urban and architectural scale (Crespo et al., 2014; Bougiatioti et al., 2015):

Solar radiation: It is defined as direct radiation, which provides important heating energy, and diffuse radiation, which defines the amount of light in the space. This factor depends on the seasons and geographical variables such us latitude, terrain topography and site orientation. Its control in traditional dwellings is essentially achieved by thermal regulation using passive devices that capture the sun rays in winter and veil them in summer (Kitous et al.,2004; Bencherif, Chaouche, 2013).

Air temperature: It is defined by the average annual temperature. It depends on altitude, sunshine, wind, soil type, etc (Viaro, Ziegler, 1983). In order to maintain a satisfactory ambient temperature in winter and summer, it is necessary to control: thermal regulation, thermal inertia ${ }^{22}$ of building materials and passive ventilation (Bencherif, Chaouche, 2013).

Winds: They are defined by their nature, power and direction. There characteristics change according to topography, geography, temperature, etc. (Viaro, Ziegler, 1983). To control the action of wind on buildings, buildings should act as a barrier to prevent air from entering indoor spaces, especially if the air is laden with sand and dust, or redirect air movement to improve passive ventilation (Nirmal, 2017).

Relative humidity: This is the ratio of water vapor in the air to the maximum amount of water vapor that the air can hold at a given temperature. Air is dry when the relative humidity is below

20 Online scientific publication for knowledge sharing and training in geography. http://geoconfluences.ens-lyon.fr/

21 https://fr.climate-data.org/

22 "Thermal inertia (or thermal mass) is the physical ability of a material to store energy. The higher the inertia, the more heat (or coolness) the material gives off to compensate for external thermal variations (because the material takes longer to heat up or cool down than air). In general, the heavier a material is, the greater its inertia. It is used in construction to attenuate variations in the outside temperature, to accumulate during the day the heat that will be released at night and, finally, to ensure an indoor climate that is as comfortable as possible" (Bencherif, Chaouche, 2013). 
$35 \%$ and humid at over $65 \%$ relative humidity. Its quantity affects thermal comfort, indoor air quality and the lifespan of building materials (Viaro, Ziegler, 1983). It is controlled by increasing indoor air temperature, improving passive ventilation, choosing appropriate building materials ${ }^{23}$.

Precipitation: It is considered to be low to slightly low between 50-250 mm/year, average between 250-500, slightly high to high between 500-2000 mm/year (Rodriguez,2013). The control of precipitation essentially involves the evacuation of the excess water that accumulates within the traditional dwellings to prevent it from damaging their foundations and structures. In warm climates, rainfall is favorable because it is a primary source of water and because it mitigates excess heat through passive evaporative cooling ${ }^{24}$ (Diaz et al., 2015).

\begin{tabular}{|c|c|c|c|}
\hline \multicolumn{2}{|r|}{ Physical factors } & Algiers kasbah & M'zab Valley \\
\hline \multirow{4}{*}{ 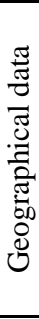 } & Latitude & $36^{\circ} 47^{\prime}$ North & $32^{\circ} 30^{\prime}$ North \\
\hline & Longitude & $3^{\circ} 3^{\prime}$ East & $3^{\circ} 3^{\prime}$ East \\
\hline & Altitude (m) & $0-120$ & 468 \\
\hline & $\begin{array}{l}\text { Climatic zone } \\
\text { (Köppen Geiger } \\
\text { classification) }^{25}\end{array}$ & $\begin{array}{c}\text { Csa Mediterranean } \\
\text { climate: Dry and } \\
\text { warm summer and } \\
\text { mild winter } \\
\end{array}$ & $\begin{array}{c}\text { BWh Warm and dry } \\
\text { desert climate: Mild to } \\
\text { warm winters, very cold } \\
\text { nights }\end{array}$ \\
\hline \multirow{3}{*}{ 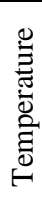 } & $\begin{array}{c}\text { Annual average } \\
\text { Min. }\end{array}$ & 11.4 & 14.78 \\
\hline & $\begin{array}{c}\text { Annual average } \\
\text { Max. }\end{array}$ & 22.9 & 27.42 \\
\hline & $\begin{array}{c}\text { Thermal } \\
\text { amplitude }^{26}\end{array}$ & Important & Very important \\
\hline \multirow{3}{*}{ 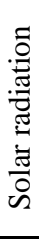 } & $\begin{array}{l}\text { Direct }{ }^{27} \\
\left(\mathrm{MJ} / \mathrm{m}^{2}\right) \\
\end{array}$ & 15.9 & 18.6 \\
\hline & Diffuse $^{28}$ & $\begin{array}{l}\text { Significant (with } \\
\text { min } 2400 \text { h/year of } \\
\text { sunshine duration) }\end{array}$ & $\begin{array}{c}\text { Important (with } 3600- \\
4000 \text { h/year : } 80-90 \% \text { of } \\
\text { diurnal period) }\end{array}$ \\
\hline & $\begin{array}{c}\text { Solar angle of } \\
\text { incidence }^{29}\end{array}$ & Intense & Very intense \\
\hline \multirow{3}{*}{ ? } & Nature & Humid and cool & $\begin{array}{l}\text { Dry, loaded with sand } \\
\text { and dust }\end{array}$ \\
\hline & Power & light to moderate & light to moderate \\
\hline & Direction & $\begin{array}{l}\text { North -East/ } \\
\text { North-West } \\
\end{array}$ & North \\
\hline \multicolumn{2}{|c|}{$\begin{array}{c}\text { Relative humidity } \\
(\%)\end{array}$} & High $(61-74 \%)$ & Very low \\
\hline \multicolumn{2}{|c|}{$\begin{array}{c}\text { Precipitations } \\
\text { (mm/year) }\end{array}$} & 671.9 & 69.11 \\
\hline
\end{tabular}

Table 1. Physical factors of the geo-climatic environment of the Algiers Kasbah and the M'zab Valley.

${ }^{23}$ http://www.level.org.nz/passive-design/controlling-indoorairquality/humidity-and-condensation/

24 Evaporative cooling is a process which takes advantage of the latent heat of evaporation of water to absorb sensible heat from the surrounding air with which it is in contact. https://www.sciencedirect.com/topics/engineering/evaporative-cooling.

25 A climate classification based on precipitation and temperatures, invented by the botanist Köppen -Geiger in 1900. https://fr.wikipedia.org/wiki/Classification_de_K\%C3\%B6ppen.

26 The thermal amplitude is the difference in temperature between day and night in a given region. It depends on latitude and clarity of air that promotes heat loss from the rocky soil and plants through night radiation (Kitous et al.,2004; Bencherif, Chaouche, 2013).

27 Direct radiation is solar radiation reaching the earth's surface directly from the sun. https://energieplus-lesite.be/theories/climat8/ensoleillement-d8/

\subsection{On the urban scale:}

At this scale, the response to the physical factors of the environment is function of seasons, urban fabric, terrain topography and site orientation (Kitous et al., 2004). In winter, due to the low altitude of the sun, solar radiation is oblique and less concentrated resulting in lower air and surface temperatures. Therefore, it is necessary to opt for an orientation that favors the longest exposure to solar radiation. In the kasbah of Algiers, the topography of the site imposes south-east orientation, which is considered very favorable to benefit from winter solar radiation (Belakehal et al., 2001). However, ksour of the M'zab valley, which are installed on hills with a radio-concentric urban layout (privileged for religious reasons) do not have a preferential orientation (Bencherif, Chaouche, 2013). This situation leads to an unequal exposure to winter solar radiation depending on the position of the buildings on the hill $\left(u b a c^{30}, a_{d r e t^{31}}\right)$. Though, in summer, the orientation of the site has a negligible effect on air temperature because the solar radiation, more vertical due to the high altitude of the sun, can reach all areas at all positions (Kitous et al., 2004).

The compactness of the traditional urban fabric, whether in the Kasbah of Algiers or in the M'zab valley, ensures a certain thermal homogeneity (Kitous et al., 2004). Compactness is often expressed in terms of height to width ratio $\mathrm{H} / \mathrm{W}$ (high buildings bordering narrow streets). The high $\mathrm{H} / \mathrm{W}$ ratio in both sites provides shade that contributes to lower air temperature and brings coolness in summer owing that to the reduction in the areas exposed to direct solar radiation. In addition, the compact geometry reduces the areas exposed to wind, which reduces heat loss in winter. In summer, the compactness acts in conjunction with the hierarchical street width layout to control air flow around and through the site allowing air to be redirected to dissipate heat (Viaro, Ziegler, 1983; Bencherif, Chaouche, 2013; Nirmal, 2017). In addition to orientation and compactness, the traditional urban fabric of both sites uses the Sabbath to create an alteration of covered and uncovered sections of the streets to enhance shade. This device allows the fresh air of the covered sections to replace the hot $\mathrm{air}^{32}$ of the open areas creating a fresh air current even in the absence of wind (Bencherif, Chaouche, 2013; Djebbar, 2018).

These devices create a favorable microclimate at both sites in winter ${ }^{33}$. However, in summer, they are not sufficient to reduce the heat in the ksour of the pentapolis because of the extremely high air temperature, the very dry atmosphere, the frequent and hot winds and the continuous exposure to intense solar radiation (Kitous et al., 2004; Adad, Mazouz, 2013). Thus, the inhabitants of the m'zab valley leave the ksour to the palm grove where the climatic conditions are softened due to the presence of water sources "M'zab wadi" and vegetation "palm trees" (Chabi, Dahli, 2011a; Djebbar, 2018), whereas in the Kasbah of Algiers, its position on the waterfront and the less extreme climatic conditions allow for natural cooling (Karabag, Fellahi, 2017).

28 Diffuse radiation is radiation received from the celestial vault. Its intensity is measured by the amount of light in the space. https://energieplus-lesite.be/theories/climat8/ensoleillement-d8/

29 "The angle of incidence is that formed by a direct electromagnetic flux (solar radiation, etc.) and a certain type of receiving surface (wall, floor, etc.). Lambert's law states that the calorific intensity per unit area varies proportionally to the sinus of the angle of incidence of the sun's rays". That is to say, the more the latitude increases, the more the angle of incidence becomes vertical and therefore more intense. (Bencherif, Chaouche, 2013)

30 Refers to the slopes of a mountain valley that benefit from the shortest exposure to the sun (Kitous et al., 2004)

31 The opposite side of the $u b a c$, benefitting from the longest exposure to the sun (Kitous et al., 2004)

32 Hot air tends to rise due to its reduced weight (Djebbar, 2018)

33 ksour maintain a high temperature during winter compared to exposed sites such as plateaux and palm grove (Kitous et al., 2004) 


\subsection{On the architectural scale}

4.3.1 Solar radiation: The intensity of solar radiation is greater in the M'zab Valley than in the Algiers Casbah because of its angle of incidence (Bencherif, Chaouche, 2013; Kitous et al., 2004). Nevertheless, the houses at both sites have succeeded to achieve thermal regulation through the following passive environmental devices:

Compact geometry and the stepped terraces: The Compact shape of traditional houses reduces the surfaces exposed to solar radiation which is inconvenient during wintertime. The layout of the houses, whether in the Kasbah of Algiers or in the M'zab valley, follows the slope of the terrain and forms stepped terraces that allow more surface area to capture solar radiation (Figure 4), and store it in the form of heat (Kitous et al., 2004; Belakehal et al., 2001; Belakehal et al., 2004; Benchakroun et al., 2019). However, in summer, it reduces the external surfaces exposed to vertical solar radiation which prevent the overheating (Bencherif, Chaouche, 2013; Kacher, Zermout, 2016).

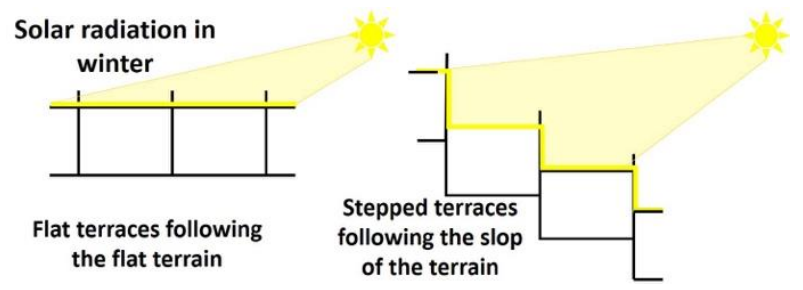

Figure 4. Schema that illustrates how stepped terraces ensure more exposure to winter solar radiation.

Wast ed dar: In the houses of the Kasbah of Algiers, wast ed dar is often a patio whose height is greater than its width (Bencherif, Chaouche, 2013). This configuration provides shade in summer without compromising the penetration of solar radiation in winter (Figure 5).

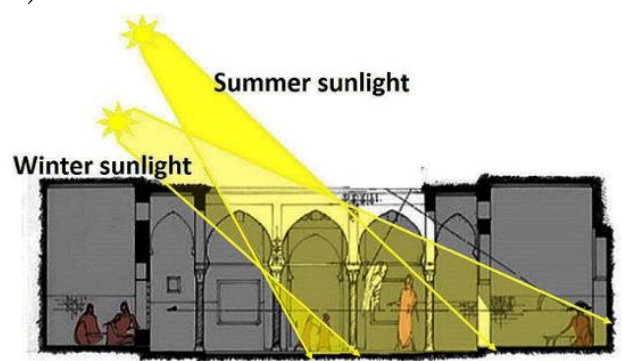

Figure 5. Solar radiation in a patio of an Algiers Casbah house (Benchekroun, 2019 treated by the authors)

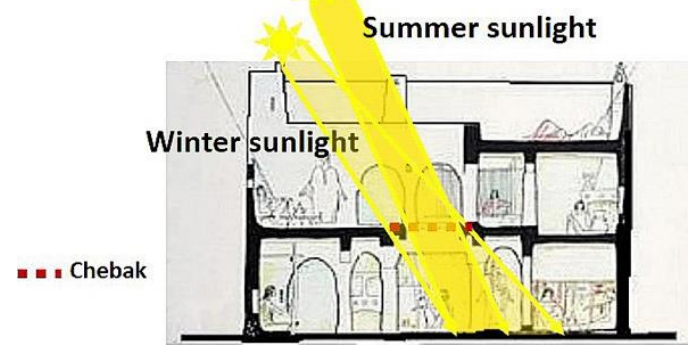

Figure 6. Spatial organisation of a mozabite house (Chabi, Dahli, 2011a treated by the authors)
In the houses of the M'zab valley, wast ed dar is composed of two types of courtyards. The first, on the ground floor, is shaded most of the day due to the small size of the opening in its roof and the presence of the chebak that can be covered with palm branches or cloth to prevent the sun's rays from penetrating it in order to provide shade (Ravéreau, 2003). The use of this space is privileged during the summer days because of the coolness brought by the shade. During summer nights, the small size of this opening no longer allows sufficient air circulation to dissipate the heat released into the air by the interior surfaces of the house, forcing the inhabitants to leave the Amesentidar for the upper courtyard in search of fresh air. In winter, the use of these two spaces is reversed to meet the needs of the inhabitants (Figure 6).

Arched galleries: They serve as a buffer space in the houses at both sites. Because of their arrangement inside the house (overlooking the courtyard), they are more exposed to solar radiation than the interior spaces, which makes them warmer and therefore favored during winter days. In summer, the galleries provide shade (Figures 7) that prevents the sun's rays from overheating the exterior surfaces of the room walls and from penetrating and overheating the air (Bencherif, Chaouche, 2013; Karabag, Fellahi, 2017; Djebbar, 2018).
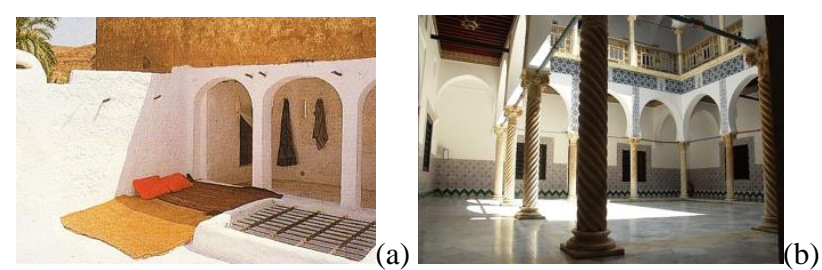

Figure 7. (a) A shaded Ikomar in a house of the M'zab valley (Ravéreau, 2003); (b) A shaded gallery in a house of the Kasbah of Algiers ${ }^{34}$.

$K^{\prime}$ bou: It overhangs a short distance of the street, helping to veil the summer's vertical solar rays while allowing the winter solar rays to reach the exterior surfaces of the walls of the houses to heat them. They are used more in the houses of the Kasbah of Algiers than in those of the M'zab valley (Bencherif, Chaouche, 2013; Kacher , Zermout, 2016; Djebbar, 2018).

Vegetation: By vegetation, we mean palm trees that are characterized by their height, which allows them to veil the sun rays and provide shade. For the M'zab valley, the presence of vegetation is essential in summer to avoid overheating of the surfaces and thus an increase in air temperature, which is not the case in winter. For that reason, in the M'zab valley, the houses of the ksour and those of the palm grove are used alternately in order to conciliate summer and winter comfort. In the kasbah of Algiers, the low intensity of solar radiation and the short duration of sunshine, among other reasons that we will see in this paper, have made the presence of vegetation not necessary or even inconvenient for conciliating winter and summer comfort (Kitous et al., 2004; Bencherif, Chaouche, 2013).

Color of houses: The houses in the Kasbah of Algiers and the M'zab Valley have the exterior surfaces painted in light colors. In the Kasbah, the main color is white (the natural color of the lime coating) because of its ability to reflect a large part of the solar radiation and to store only a small part of it and thus protect the exterior surfaces from overheating (Figure 8).

\footnotetext{
34 https://www.visa-algerie.com/12-bonnes-raisons-de-visiter-lacasbah/
} 
However, this color is unsuitable in the M'zab Valley because of the very high intensity of sunlight and its long duration, which causes glare. for this reason, the external facades of mozabite houses have a chromatic appearance characterized by the use of sandy/earthy colors (Figure 9) which result from the use of natural pigments (Corpus, Meda Programme, 2001; Gouaich et al., 2018).

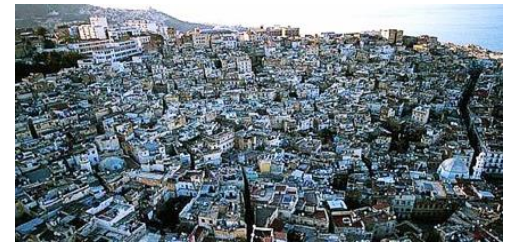

Figure 8. General view of the Kasbah of Algiers ${ }^{35}$

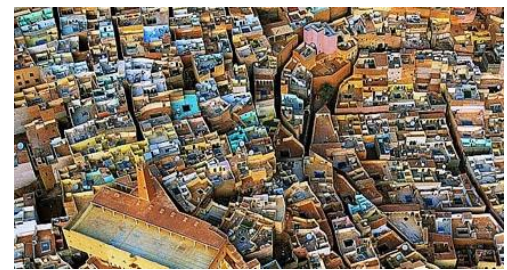

Figure 9. General view of the Kasr "El Attef" in the M'zab (Gouaich et al., 2018)

Openings: In traditional houses, solar radiation (diffuse radiation) is the main source of light. The introverted dwellings capture most of their light from the wast ed dar. In the Kasbah of Algiers, there are many openings (windows, doors, etc.) which have different dimensions and positions on the surface of the wall, most of them overlook the patio. The windows (at eye level when sitting) and the doors (designed to be wide open most of the time) are the main openings that allow light to enter the interior spaces (bedrooms, kitchen, etc.). In the M'zab valley, on the other hand, all the interior spaces are wide open to the wast ed dar and therefore directly illuminated by the light penetrating from the chebak (Ravéreau, 1989; Ravéreau, 2003).

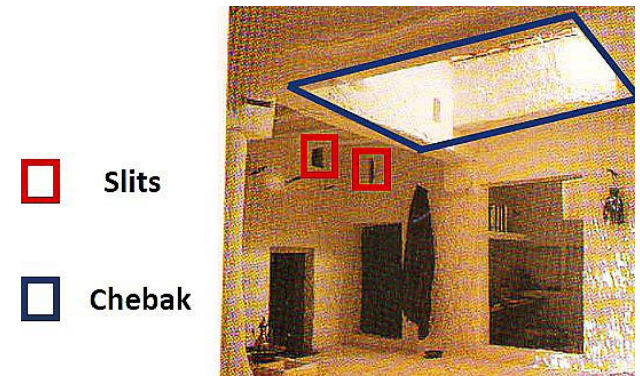

Figure 10. The Amesentidar in the house of the M'zab valley (Ravéreau, 2003)

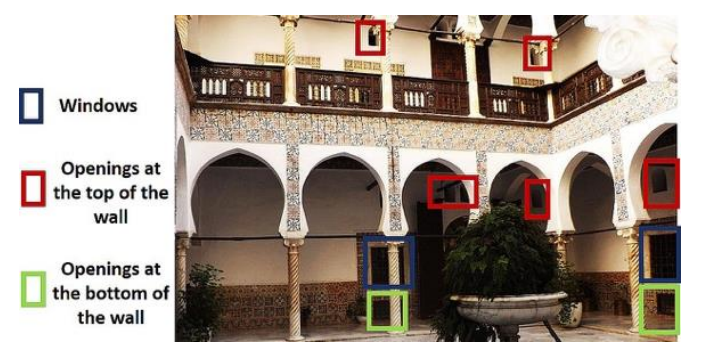

Figure 11. The patio in the house of the Kasbah of Algiers ${ }^{36}$ (Ravéreau, 2003)

\footnotetext{
http://cnra.dz/atlas/casbah-dalger/\#!

${ }^{36} \mathrm{https}: / /$ prescriptor.info/site/3061/la-casbah-d-alger-entre-hier-etaujourd-hui
}

Moucharabieh (claustra): A form of solar protection that covers the entire surface of windows, especially those facing the outside, allowing natural light to enter through the holes. This environmental device is used in houses at both sites (Ravéreau, 1989; Ravéreau, 2003).

4.3.2 Air temperature: In order to realize thermal regulation and conciliate both summer and winter comfort, the houses of both sites have used the following passive environmental devices:

Compact geometry: The compact form of the houses is a device that reduces the number of surfaces exposed to the sun's rays and cold wind, thus reducing heat loss in winter and heat gain in summer. It is used in the houses at both sites (Chabi, Dahli, 2011b).

Building materials: The choice of materials for traditional houses depends on their availability and their thermo-physical characteristics (Bencherif, Chaouche, 2013). Traditional houses in Algiers and M'zab use natural and local materials such as adobe, stone, raw brick, timchent ${ }^{37}$ and lime, characterized by their high thermal inertia which allows them to store the sun's energy during the day. The high thermal inertia of these building materials allows the introduction of a phase shift in the restitution of heat (or coolness) which delays the time of overheating of the interior parts in summer, and the time of cooling in winter (Corpus, Programme Meda, 2001; Kitous et al, 2004; Chabi, Dahli, 2011b; Bencherif, Chaouche, 2013).

Thickness of the walls: The traditional houses are characterized by their too thick walls. In the houses of the kasbah of Algiers, the thickness of the walls varies between 60 and $80 \mathrm{~cm}$, whereas in the houses of the M'zab valley, the walls can be up to $1 \mathrm{~m}$ thick due to the extreme climatic conditions that prevail there (Kacher, Zermout 2016; Chabi, Dahli, 2011b). This device is very important to obtain passive thermal regulation " The thicker the wall, the longer the time of phase shift " (Bencherif, Chaouche, 2013).

The Wast ed dar: In traditional houes, the wast ed dar provides both cooling and heating functions. For heating, it ensures the penetration of direct solar radiation to the spaces surrounding it, which store the thermal energy provided by the sun, due to the high thermal inertia of their internal surfaces (walls, floor, etc.), and then release it into the air in order to maintain a satisfactory ambient temperature during winter nights. For cooling, this device ensures, in the houses of the Kasbah, a passive ventilation called "chimney effect" owing that to the depth of the patio which enables it to suck in the hot air, tending to rise naturally, driven out by the fresh air (Figure 12). The resulting air movement ensures the ventilation of the house (Bencherif, Chaouche, 2013; Adli-Chebaiki, ChabbiChemrouk, 2015). This effect is less important in the house of M'zab because of the shallow depth of its wast ed dar. In addition, the need to cover the chebek at certain times of the day requires theuse of other devices to ensure the ventilation of the dwelling (Ravéreau, 2003; Chabi, Dahli, 2011b).

Openings: The introversion of the traditional houses offers them two fronts: one front facing the street with some small openings at the top of the wall and another front overlooking wast-ed-dar and pierced with several openings of different sizes and heights (Figure 11). These openings, facing each other, work all together to ensure a "transversal ventilation" of the house (Figure 12). In the kasbah of Algiers, this ventilation is ensured, mainly by the small openings of the external and internal facade.

\footnotetext{
37 The Timchemt is a local plaster extracted from a surface layer. It has a yellowish or reddish color in its nature quarry, and it becomes white after burning it in the oven
} 
The small openings at the bottom of the walls allow the entry of fresh air from outside (street or courtyard) while those at the top allow the evacuation of warm air (Ravéreau, 1989; Benchekroun, 2019).

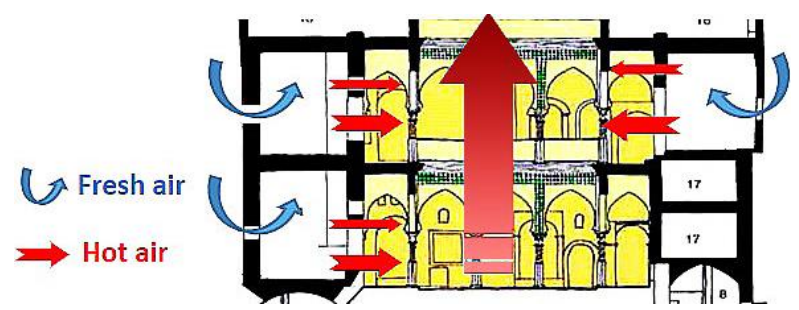

Figure 12. Chimney effect and transversal ventilation in a house of the Kasbah of Algiers (Benchekroun, 2019 treated by the authors)

The same thing in the houses of M'zab (Figure 13) with the difference that the openings in this house are fewer and even smaller than those in the Algiers house (generally slits not exceeding $7 \mathrm{~cm}$ in width, arranged at different heights) (Ravéreau, 2003). Other larger openings are located at the top of the wall overlooking the street, but generally equipped with a moucharabieh (Chabi, Dahli, 2011b; Bencherif, Chaouche, 2013). Also, kasbah houses use a small screened opening above the front door to let in shaded air from the street (for the Mozabite house, the air enters directly through the Taskift because the front door is always open) which passes through the cooler basements, if they exist, before entering the wast ed dar (Corpus, Meda programme, 2001).

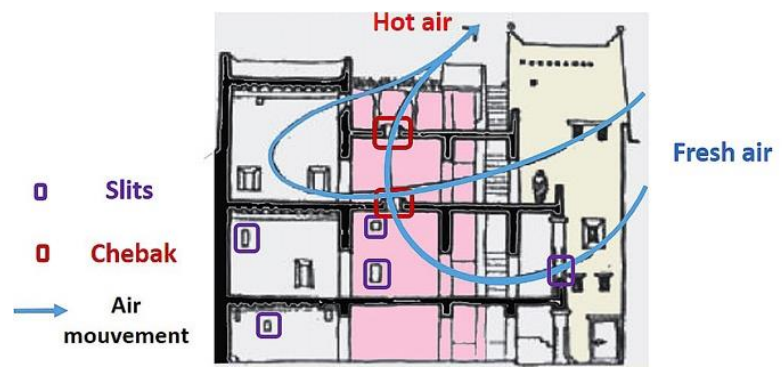

Figure 13. Air circuits through the houses in the M'zab Valley (Bencherif, Chaouche, 2013 treated by the authors)

Vegetation: This device is only used in the palm grove of M'zab. The low thermal inertia of the plants (they do not radiate heat at night) and their transpiration capacity accelerate the cooling process of the air and surfaces at night and thus the loss of heat, which causes a strong thermal amplitude (Kitous et al., 2004). This process is recommended in summer because it provides a satisfactory ambient temperature at night, whereas it is inconvenient in winter.

4.3.3 Wind: both houses use environmental devices adapted to the wind characteristics of their sites:

Compact geometry: The compact shape of the houses at both sites reduces the areas exposed to wind, thus avoiding heat loss. This helps to maintain a satisfactory ambient temperature during winter. In summer, the reduced heat loss causes an overheating at the interior. This is compensated by the hierarchical layout of the streets at both sites, which allow the wind speed to accelerate, creating a draught of fresh air and then carrying it inside the houses.
Wast ed dar: This device allows the houses at both sites to act as a barrier against wind (cold, hot, sand and dust-laden) by diminishing the number and size of openings overlooking the street. In addition, the depth of the patio of the Kasbah houses prevents the wind from penetrating inside (Bencherif, Chaouche, 2013), while in the houses of M'zab, the chebak, which can be covered, prevents the penetration of winds laden with sand and dust (Ravéreau, 2003).

4.3.4 Precipitations: Beside its impact on the microclimate at both sites, the force and frequency of precipitation strongly influences the shape of the roof (Rodriguez, 2013). Sloped roofs are required in regions where precipitations are intense and frequent while flat ones are used in dry regions:

Flat roofs: In the houses of the M'zab, it is not necessary to evacuate rainwater because of the scarcity of rainfall. For this reason, the builders opted for a flat roof that allows the houses to gain both compactness and space by offering the inhabitants an open space inside the house (the terrace) that can be used at different seasons and different times of the day. The same applies to the houses in the Kasbah, except that the intensity of the rains requires a low-sloped roof to evacuate rainwater (Rodriguez, 2013), which must be compensated for by the use of other devices.

$\boldsymbol{E l} \boldsymbol{j} \boldsymbol{j e b}:$ In the Kasbah of Algiers, $e l$ jeb is used to store rainwater that accumulates either in the patio or on the terrace. In fact, the presence of excess water can cause serious damage to the structure of the house as well as to the health of the inhabitants due to water infiltration and humidity resulting from its stagnation on the terrace. For this reason, the Kasbah houses use a rainwater collection system that evacuates the accumulated water (using ceramic pipes built into the walls) and stores it in an underground cistern called Jeb (Missoum,2003)

4.3.5 Relative Humidity: The difference between the relative humidity in both sites is highlighted by the use of different devices in the houses at both sites:

Vegetation: This device is not used in the Kasbah of Algiers because of the high relative humidity there. However, in the M'zab valley, the relative humidity is too low, which is very advantageous in winter for health conditions (avoid humidity) and the lifespan of building materials. On the other hand, in summer, the inhabitants move towards their houses in the palm grove because the presence of vegetation reduces the harshness of the climatic conditions due to the transpiration capacity of the plants which contribute to the humidification of the air.

Building materials: Houses of the Algiers Kasbah use materials that regulate air humidity (raw brick, lime) due to the high relative humidity there. These materials allow the walls to breathe and thus reduce humidity, which is beneficial for both health conditions and the materials lifespan ${ }^{38}$.

Openings and wast ed dar: These devices make it possible to multiply the ventilation systems, which is highly recommended in the traditional houses of Algiers compared to the Mozabite houses, in order to protect the building materials from moulds formed by excess humidity in the air and, and thus ensure the longevity of the building materials. "The higher the humidity, the more ventilation is required" (Rodriguez, 2013).

\footnotetext{
38 Manuel des bonnes pratiques architecturales. http://susplugasjeanphilippe.over-blog.com/2017/07/
} 


\section{CONCLUSION}

This paper examines the variety of geo-climatic environments and their impact on traditional architectural expression. According to the literature review, it is necessary to involve all scales: urban, architectural and technical when analyzing the adaptation of traditional architecture to its environment. The physical factors of the geo-climatic environment act in totality on traditional dwellings, which leads these latter to adapt by developing environmental devices that function in totality to respond to them. The comparison between the traditional houses of Algiers and M'zab has allowed us to understand that the passive environmental devices are, for the majority, common to the two typologies without being identical (used differently according to each geoclimatic context). Furthermore, it has highlighted the fact that these different environmental devices are often combined together to form a kind of one unified system that suffers in case of failure of one of these devices (Ghodsi 2012). The intelligence in using the same environmental device in different ways by modifying its characteristics (its dimensions, its layout within the house, etc.) and/or associating it with other environmental devices so as to constitute, all together, a new system is the answer to our initial question on how these devices can adapt to different geo-climatic contexts, which is known as "Genius of Civilizations".

\section{REFERENCES}

Abdelsalam, T., Mohamed Rihan, G., 2013. The impact of sustainability trends on housing design identity of Arab cities.

Adad, M.C., Mazouz, M.T; 2013. Les anciens et nouveaux ksour : Etude comparative. Cas du M'zab. Courrier du savoir.

Adli-Chebaiki, L., Chabbi-Chemrouk, N., 2015. Vernacular Housing in Algiers: A Semantic and Passive Architecture. International Journal of Design \& Nature and Ecodynamics 10

Belakehal, A., Aoul, K.T., Bennadji, A., 2001. Sunlight in the traditional dwellings of Algeria. International Lighting Congress, 10.

Belakehal, A., Aoul, K.T., Bennadji, A., 2004. Sunlighting and Daylighting Strategies in the Traditional Urban Spaces and Buildings of the Hot Arid Regions. Renewable Energy 29 (5)

Bellal, T., Tacherifte, A., 2003. Spatial arrangements in traditional m'zabite houses. Sciences \& Technologie. A, Sciences Exactes 0 (19), 121-38.

Benchekroun, M., Chergui, S., Ruggiero, F., Di Turi, S ., 2019. Indoor Microclimate Conditions and the Impact of Transformations on Hygrothermal Comfort in the Old Ottoman Houses in Algiers, International Journal of Architectural Heritage.

Bencherif, M., Chaouche, S., 2013. The urban courtyard house as an architectural response to the climatic constraints of the arid environment. Sécheresse 24 (3), 203-13.

Bougiatioti, F., Papagiannakis, M., Oikonomou, A., 2015. Environmental Aspects of the Vernacular Architecture of NW Greece. The settlement of Psarades.

Bousquet, C., 2002. L'habitat mozabite au M'Zab. In Habitat, État, société au Maghreb, édité par Pierre Robert Baduel, 257-69. CNRS Éditions.

Chabi, M., Dahli, M., 2011a. Une nouvelle ville saharienne Sur les traces de l'architecture traditionnelle.
Chabi, M., Dahli, M., 2011b. Le Ksar de Tafilelt dans la vallée du Mzab : Une expérience urbaine entre tradition et modernité. https://www.academia.edu/36563506.

Corpus., 2001. MEDA program publications for mediterranean traditional architecture http://www.meda-corpus.net/frn/portails.

Crespo, I., Barrera, M., Ramos, L., 2014. Climatic Analysis Methodology of Vernacular Architecture. In Vernacular Architecture: Towards a Sustainable Future.

Diaz, C.A., Osmond, P., King, S., 2015. Precipitation and Buildings: Estimation of the Natural Potential of Locations to Sustain Indirect Evaporative Cooling Strategies through Hot Seasons, 10.

Djebbar, K.E., 2018. Ksours in algeria, lessons of environmental performance for a more sustainable future, 2: 20.

Gouaich, Y., Mebrouki, A., Ghariri, R., Mebarki, A., Belabbas, A., Manav, B., Serra, J., Llopis, J., Torres, A., 2018. A Novel Method for Assessing the Chromatic Integration of Architecture in the Ksourian Landscape of M'zab Valley, Algeria. Color Research \& Application 43 (5), 760-78.

Ghodsi, H., 2012. Vernacular Architecture: Solution to a More Sustainable Future. ResearchGate. https://www.researchgate.net/publication/259278928

Kacher, S., Zermout, H., 2016. Environmental Implication of the Algerian Traditional House. Édité par Professor Chafic-Thomas Salame. Management of Environmental Quality.

Karabag, N., Ebru, Fellahi, N., 2017. Learning from Casbah of Algiers for More Sustainable Environment. Energy Procedia

Kitous, S., Djenane, M., Daoudi, N., Boussoualim, A., Bensalem, R., Adolphe, L., 2004. Thermal Behaviour of Compact Urban Fabric in Hot and Dry Climate: Case Study of M'zab Valley. Experimental Results. ResearchGate.

Nasri, M., 2007. Deterioration du patrimoine architectural des Ksour. Cas du Ksar de khanguet Sidi Nadji. Biskra, Université Mohamed Khider. Faculté des Sciences de l'Ingénieur.

Nirmal, Ar. V.K., 2017. Wind and Architecture: Design to the Flow. 04 (11), 7.

Novelli, V., D’Ayala, D., 2012. Seismic Vulnerability Assessment of the Casbah of Algiers.

PPSMVSS., 2017. Plan permanent de sauvegarde et de mise en valeur des secteurs sauvegardés. Alger: OGEBC

Ravéreau, A., 1989. La Casbah d'Alger, et le site créa la ville. Paris, Sindbad

Ravéreau, A., 2003. Le M'zab, une leçon d'architecture. Actes Sud, Sindbad.

Rodriguez, G., 2013. Modélisation de la réponse de l'architecture au climat local, 219. https://www.researchgate.net/publication/317300672

Viaro, A.M., Ziegler, A., 1983. Habitat traditionnel dans le monde: éléments pour une approche. Archive ouverte UNIGE. 1983. https://archive-ouverte.unige.ch/unige:24179. 